Kalpa Publications in Engineering
Volume 1, 2017, Pages 200-207
ICRISET2017. International Conference on Re-
search and Innovations in Science, Engineering
\&Technology. Selected Papers in Engineering

\title{
Small Signal Stability Analysis of Power System with Increased Penetration of PV Generation
}

\author{
David Parmar ${ }^{1}$, Dr.Bhinal Mehta ${ }^{2}$ \\ M\&V Patel Department of Electrical Engineering, C. S. Patel Institute of Technology, \\ CHARUSAT- Changa, Anand, Gujarat, India \\ davidparmar20@gmail.com, bhinalmehta.ee@charusat.ac.in
}

\begin{abstract}
With the increase in the penetration of photo-voltaic (PV) generation in the power system it is utmost important to analyze the impact and issues of PV generation on the interconnected power system. As the output of PV is not constant its influence on the power system stability needs to be considered and it is evident from the grid codes of most of the countries. In this paper two different model of solar photovoltaic generation suitable for small signal stability analysis are presented and its behavior is investigated considering the IEEE 14-bus test system. The research review the impact of solar power on the interconnected power system with a high penetration of PV generation by the control of active and reactive power output. Based on constant reactive power and constant voltage magnitude models, the effect of voltage and angle stability of grid connected PV systems are studied and discussed. The eigenvalue analysis is carried out for the test system without any PV penetration and with different PV penetration levels and the results are compared using the power system analysis toolbox on MATLAB platform. The most influencing critical modes are identified and their behavior with increase in PV penetration is demonstrated.
\end{abstract}

\section{Introduction}

As the effects of global warming are increasing tremendously these days, the amount of renewable energy integration is growing worldwide and among these renewables solar photovoltaic installations are given tremendous boost by the government in developing countries like India. The solar energy is the major option among renewable energy resources to satisfy the energy needs. Government of India has set the ambitious target of deploying $172 \mathrm{GW}$ by 2022 and among these renewables grid-connected solar PV will be given high preference [1].

With the large-scale integration of the PV generation to the existing power system its impact on power system stability needs to be analyzed more carefully due to its detrimental and beneficial impact as the PV generators have characteristics that are different from the conventional synchronous generators. As the solar power plant mainly consists of the PV modules inverters, they do not possess 
inertia which the traditional synchronous generators possess due to the rotating mass. Also, the behavior and interaction of these solar power plants with the power system depends on the dynamics of the inverter. Therefore, it is utmost important to study the impact of the penetration level of PV generation on the dynamic performance of power system.

The impact of the PV systems connected to the utility side and rooftop PV generation connected to transmission/sub transmission system are discussed in [2]- [5]. The impact of PV generation on small signal stability considering the probabilistic analysis is discussed in [6], [7]. The voltage stability and sensitivity analysis are depicted.

In the present paper, two different models for the large PV generations are connected at the transmission system are put forward for consideration by showing its impact on IEEE 14-bus test system. The proposed models are much simple, generic and can be readily implemented. The objective of the paper is to do the detailed small signal stability analysis and voltage stability analysis of the PV generation with the high penetration level. The structure of the remaining is as follows: Section 2 dealt with modeling of PV models followed by proposed approach in Section 3. The results of different cases are demonstrated in Section 4 along with its discussion. The conclusions of the paper are mentioned in Section 5.

\section{Pv Modeling}

Power system stability is a property of a power system which enables it to remain in a state of operating equilibrium under normal operating conditions and to regain an acceptable state of equilibrium after being subjected to a disturbance [8]. The two different models suitable for small signal stability and voltage stability analysis are given below considering the NERC standards.

\subsection{Modelling of PV systems}

The PV generation model can be based on thinking approach of the grid side model that is like type 4 wind turbine generator (WTG) that have almost the same characteristics because both solar and wind are usually connected to the grid through a convertor and should perform nearly similar operations. [5]. Fig. 1 shows atypical type 4 WTG WECC generic model. All the generated power from the generator preferably permanent magnet synchronous generator (PMSG) is transferred to the grid through back to back voltage source converter familiarly known as generator side convertor (GSC) and network side convertor (NSC) via DC link. The NSC controls the reactive power output and voltage at point of common coupling (PCC). To do the similar task in these paper two models of PV generation are given below in Fig.2 and Fig.3 as follow:

- Model 1: PQ control model

- Model 2: PV control model

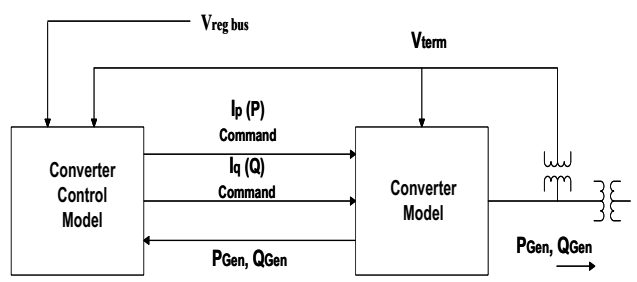

Figure 1: Type 4 wind turbine generator general block diagram

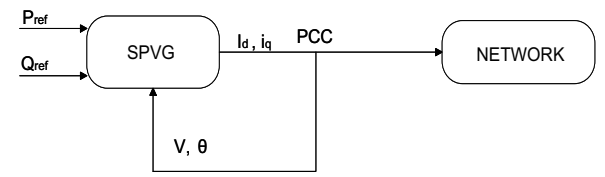

Figure 2: Model 1

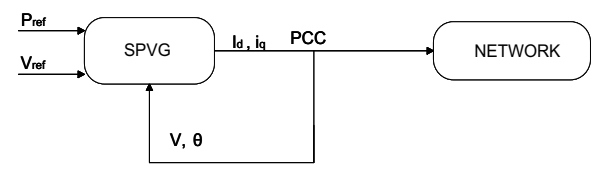

Figure 3: Model 2 


\subsection{Grid-Side Model}

The Model 1 and Model 2 in single line diagram as per the control modes are shown in both fig. 2 and fig. 3 respectively. The block diagram also depicts the equations for inverter transfer functions, the closed loop controller transfer function with unity value of steady state gain. The block-diagrams of the two SPVG models shown in fig. 4 and fig. 5 respectively. In these two models, the reference current $i_{\text {dref }}$ and $\mathrm{i}_{\mathrm{qref}}$ of the $\mathrm{d}$ axis and $\mathrm{q}$ axis are generated as per the desired reference active power and reactive power, $\mathrm{P}_{\text {ref }}$ and $\mathrm{Q}_{\text {ref }}$ respectively.

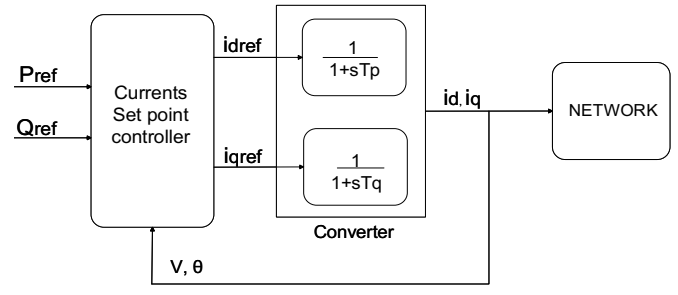

Figure 4: Model 1 block diagram

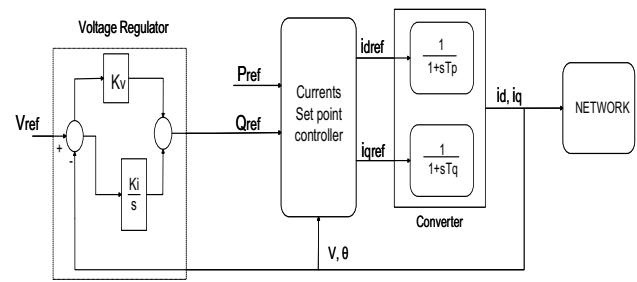

Figure 5: Model 2 block diagram.

\section{Proposed Approach}

\subsection{Small Signal Stability}

Small signal stability analysis is carried out by obtaining a linearized model of the nonlinear system and then the state space model is created. The initial conditions are obtained at the operating point. The eigenvalue $(\lambda)$ of the state matrix $A$ is obtained and the stability of the system is analyzed. The frequency of oscillations and damping ratio is obtained by right eigenvector $(\phi)$ and left eigenvector $(\psi)$. The most critical influencing modes are identified along with their percentage participation. The basic equations used for the eigenvalue analysis are as follows: [8]

$$
\begin{gathered}
A \phi_{i}=\lambda_{i} \phi_{i} \\
\psi_{i} A=\lambda_{i} \psi_{i}
\end{gathered}
$$

For the complex pair of eigenvalue related to an oscillatory mode of the system, the frequency $(f)$ and the damping ratio $(\zeta)$ are expressed as

$$
\begin{aligned}
& \lambda_{i}=\sigma_{i} \pm j w_{i} \\
& f_{i}=\frac{w_{i}}{2 \pi} \\
& \zeta_{i}=-\frac{\sigma_{i}}{\sqrt{\sigma_{i}^{2}+w_{i}^{2}}}
\end{aligned}
$$

The equation (5) shows that damping ratio, and its relationship with real part of the eigenvalue, this ratio shows the rate at which the amplitude of oscillations decreases.

\subsection{Test System}

All numerical studied load flow analysis, continuation power flow, voltage stability analysis, eigenvalue analysis and time domain simulation were performed in power system simulation toolbox (PSAT) using a MATLAB platform. The IEEE 14-bus test system shown in fig. 6 is used. The base system considered main synchronous generator (SG) whose rating is 615 MVA connected at bus 1 , and one $40 \mathrm{MW}$ smaller synchronous generator connected at bus 2 . The generator at bus 2 is replaced with PV generator of the same rating allowing a real modelling effect. The AVRs were connected to SG and the three synchronous condensers are connected at buses 3,6 and 8 . The active power and reactive power of base system load is considering 362.6 MW and 113.96 MVAr, respectively. 


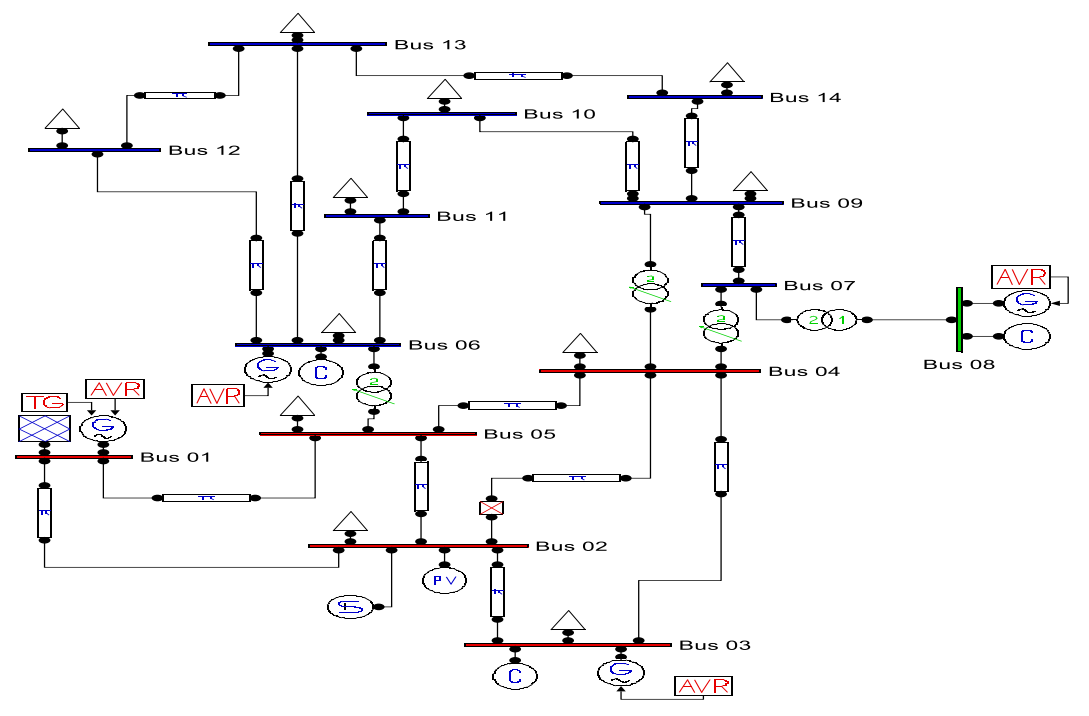

Figure 6: IEEE 14-bus test system

The following steps are considered for the proposed approach:

- The eigenvalue analysis is carried out of the system without any PV penetration and the critical modes of the systems are identified. This is taken as base case.

- Then the eigenvalue analysis is carried out of the system with the various levels of the utility scale PV penetration in the system.

- The both models are considered for PV penetration.

- The obtained results without and with PV generation are compared and the impact of the PV penetration on the stability of the system is observed.

- The obtained results of the eigenvalue analysis are validated using transient stability analysis by performing time domain analysis of the system by exciting the critical modes of the system.

The PV penetration definition used based on available generation in the system base case and PV penetration levels based on system maximum load or by the amount of energy served for one year are defined as follows:

$$
\begin{aligned}
\text { PV Penetration }(\%) & =\frac{\text { Total PV generation }(M W)}{\text { Total generation }(M W)} \\
P V_{\text {Penetration }} & =P V_{\text {penetration }} \times c . f
\end{aligned}
$$

The capacity factor (c.f) of the PV systems is considered as $25 \%$.

\section{Results \& Discussion}

The Table 1 shows the summary of the power system considering IEEE-14 bus test system which includes system generation data, system load data and system total losses. The summary of PV penetrations as defined above is presented in table 2 .

\begin{tabular}{|c|c|}
\hline \multicolumn{2}{|c|}{ TOTAL GENERATION } \\
\hline REAL POWER [MW] & 392.0304 \\
\hline REACTIVE POWER [MVAr] & 204.2345 \\
\hline TOTAL LOAD & 362.6 \\
\hline REAL POWER [MW] & 113.96 \\
\hline REACTIVE POWER [MVAr] & 29.4304 \\
\hline TOTAL LOSSES & 90.2745 \\
\hline REAL POWER [MW]
\end{tabular}

Table 1: System Description 


\begin{tabular}{|c|c|c|c|c|c|}
\hline $\begin{array}{c}\text { PV Generation } \\
\text { (MW) }\end{array}$ & 80 & 160 & 235 & 314 & 392 \\
\hline $\begin{array}{c}\text { PV } \\
\text { Penetration } \\
\text { Level (\%) }\end{array}$ & 20 & 40 & 60 & 80 & 100 \\
\hline $\begin{array}{c}\text { PV } \\
\text { Penetration } \\
\text { Level by } \\
\text { energy }\end{array}$ & 5 & 10 & 15 & 20 & 25 \\
\hline
\end{tabular}

Table 2: summary of PV penetration levels

\begin{tabular}{|c|c|c|c|}
\hline Real part & Imag. Part & Frequency & Damping (\%) \\
\hline-1.895 & 10.2699 & 1.6621 & 18.14565888 \\
\hline-1.7931 & 10.7194 & 1.7298 & 16.49838461 \\
\hline-1.3123 & 8.9507 & 1.4398 & 14.5063399 \\
\hline-0.2319 & 2.5332 & 0.40486 & 9.117869293 \\
\hline
\end{tabular}

Table 3: Critical Modes: Base case

Small signal stability analysis is carried out for base case and two PV models. The most critical modes are identified for all three cases. The critical values of the system are identified from the eigenvalue analysis and are decided that modes having a frequency of $0.01-2 \mathrm{~Hz}$ as well as damping having less than $20 \%$ are observed. A disturbance which excites the most detrimentally impacted critical modes with increased penetration level of PV is simulated. The main aim of this work is to study how the system behave with decreased system inertia and therefore in this study only most critical modes carefully considered. These eigenvalues are shown in Table 3,4 and 5 along with frequency of oscillations and damping percentage.

\begin{tabular}{|c|c|c|c|c|}
\hline $\begin{array}{c}\text { Penetration } \\
\text { (\%) }\end{array}$ & $\begin{array}{c}\text { Real } \\
\text { Part }\end{array}$ & $\begin{array}{c}\text { Imag. } \\
\text { Part }\end{array}$ & $\begin{array}{c}\text { Frequency } \\
\text { (Hz) }\end{array}$ & $\begin{array}{c}\text { Damping } \\
\text { (\%) }\end{array}$ \\
\hline 20 & -1.290 & 8.875 & 1.4274 & 14.38669 \\
\hline 40 & -0.311 & 2.250 & 0.36159 & 13.7059 \\
\hline 60 & -0.310 & 2.250 & 0.36155 & 13.655531 \\
\hline 80 & -0.308 & 2.250 & 0.36151 & 13.60211 \\
\hline 100 & -0.307 & 2.250 & 0.36147 & 13.54810 \\
\hline
\end{tabular}

Table 4: Critical Modes: Model 1

\begin{tabular}{|c|c|c|c|c|}
\hline Penetration & Mode1 & Mode2 & Mode3 & Mode4 \\
\hline $20 \%$ & -0.57654 & -1.3563 & -3.3958 & -1.2903 \\
\hline $40 \%$ & -1.0508 & -3.9798 & -2.9597 & -0.31139 \\
\hline $60 \%$ & -1.051 & -3.9798 & -2.9598 & -0.31021 \\
\hline $80 \%$ & -1.0511 & -3.9798 & -2.9598 & -0.30896 \\
\hline $100 \%$ & -1.0512 & -3.9798 & -2.9599 & -0.30771 \\
\hline
\end{tabular}

Table 6: Real part of Eigenvalue: Model 1

\begin{tabular}{|c|c|c|c|c|}
\hline $\begin{array}{c}\text { Penetration } \\
\text { (\%) }\end{array}$ & $\begin{array}{c}\text { Real } \\
\text { Part }\end{array}$ & $\begin{array}{c}\text { Imag. } \\
\text { Part }\end{array}$ & $\begin{array}{c}\text { Frequency } \\
(\mathbf{H z})\end{array}$ & $\begin{array}{c}\text { Damping } \\
(\mathbf{\%})\end{array}$ \\
\hline 20 & -0.687 & 9.8605 & 1.5732 & 6.954068 \\
\hline 40 & -0.813 & 9.8185 & 1.5682 & 8.252651 \\
\hline 60 & -0.932 & 9.7832 & 1.5641 & 9.489245 \\
\hline 80 & -1.064 & 9.752 & 1.5613 & 10.84017 \\
\hline 100 & -1.201 & 9.73 & 1.5603 & 12.25532 \\
\hline
\end{tabular}

Table 5: Critical Modes: Model 2

\begin{tabular}{|c|c|c|c|c|}
\hline Penetration & Mode1 & Mode2 & Mode3 & Mode4 \\
\hline $20 \%$ & -3.9853 & -3.0249 & -2.2786 & -0.68737 \\
\hline $40 \%$ & -3.9822 & -3.005 & -2.2567 & -0.81306 \\
\hline $60 \%$ & -3.9794 & -2.9842 & -2.2319 & -0.93256 \\
\hline $80 \%$ & -3.9765 & -2.959 & -2.2 & -1.0634 \\
\hline $100 \%$ & -3.9738 & -2.9297 & -2.1606 & -1.2015 \\
\hline
\end{tabular}

Table 7: Real part of Eigenvalue: Model 2

Table 6 and 7 depict the real part of eigenvalue of the critical modes for model 1 and model 2, respectively with the increased in PV penetration level. Fig. 7 and Fig. 8 shows the comparison of all four critical modes for model 1 and model 2 respectively as the PV generation rises. The result reveals that for model 1 the system is more stable as a real part of mode 1,2 and 4 increases, whereas for model 2 the modes are not much affected. It can be overall concluded that as penetration level increases the stability increases which is beneficial impact.

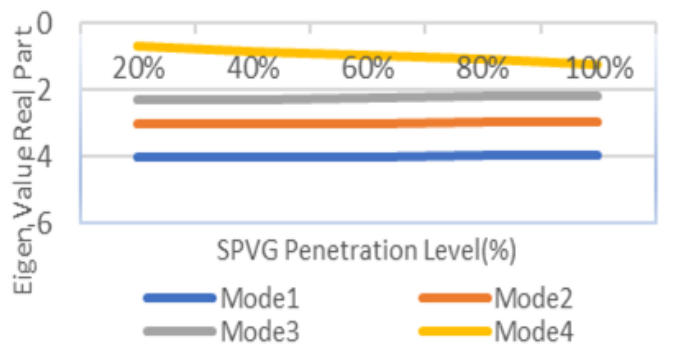

Figure 7: Real Part of eigenvalue as PV Penetration Level Increases: Model 1

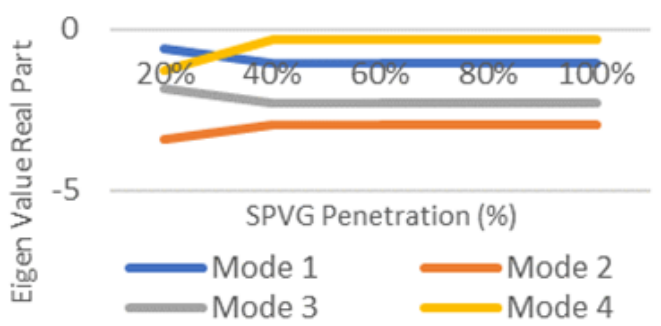

Figure 8: Real Part of eigenvalue as PV Penetration Level Increases: Model 2 


\subsection{Voltage Stability Analysis}

The load flow and continuation power flow is carried out by increasing the loading level up to certain point after which the voltage collapse for all three cases. The voltage profile of Bus 1,2,4 and 14 are examined. The results are shown in Fig. 9 -Fig 12 and Table 8. In case of voltage stability analysis Model 2 gives better results compare to base case under normal and contingency conditions, while Model 1 gives best result under normal condition and poor result under contingency conditions.

\begin{tabular}{|c|c|c|}
\hline & $\begin{array}{c}\text { Normal Condition } \\
\text { (MW) }\end{array}$ & $\begin{array}{c}\text { Contingency } \\
\text { Condition (MW) }\end{array}$ \\
\hline Base Case & 602.2376 & 560.99 \\
\hline Model 1 & 591.14 & 591.14 \\
\hline Model 2 & 698.52 & 698.52 \\
\hline
\end{tabular}

Table 8: Voltage Stability Margins

\begin{tabular}{|c|c|c|}
\hline & $\begin{array}{c}\text { Normal } \\
\text { Condition (MW) }\end{array}$ & $\begin{array}{c}\text { Contingency } \\
\text { Condition (MW) }\end{array}$ \\
\hline $\begin{array}{c}\text { Base } \\
\text { Case }\end{array}$ & 618.87 & 561 \\
\hline Model 1 & 717.216 & 543.52 \\
\hline Model 2 & 628.520 & 601.62 \\
\hline
\end{tabular}

Table 9: Oscillatory Stability Margins

\subsection{Angle stability}

Due to the continuous operation of AVR the system becomes oscillatory unstable with the increase in the loading level after certain point. The Table 9 shows the result of frequency oscillations which appear for both models and system conditions.

A time domain simulation considering the contingency was carried out by taking the line 2-4 trips at 20 seconds. The results for bus frequency and voltage magnitudes are shown in Figs.13-16 for both models. It is observed that at initial condition the system is stable, and after contingency occurs the system shows oscillatory behavior.

The table 9, it is shown that the loadability margins are going to increased when an PV generation model replaces the conventional generator particularly in model 2 which is PV-control mode. It can be noticed that voltage regulator which is used in PV-control mode has a same effect on system damping similar as of PSS. Fig 17 and Fig. 18 shows that by tuning the gains of voltage controller properly the system damping can be increased until the oscillations were totally disappear.

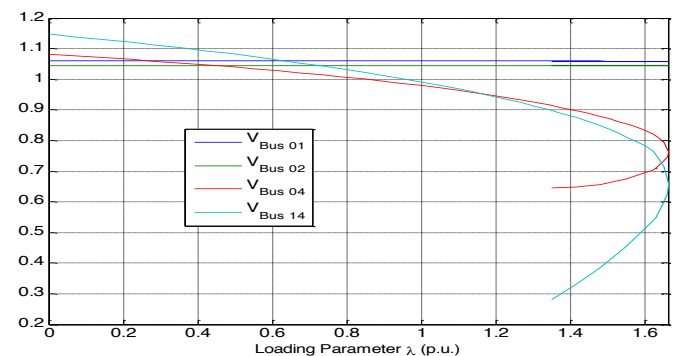

Figure 9: Voltage profile: Model 1: normal condition

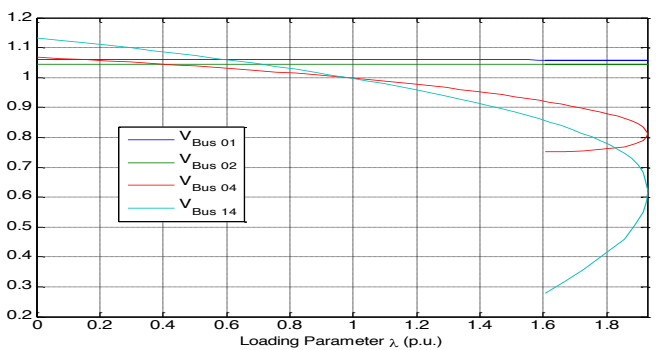

Figure 11: Voltage profile: Model 2: normal conditions

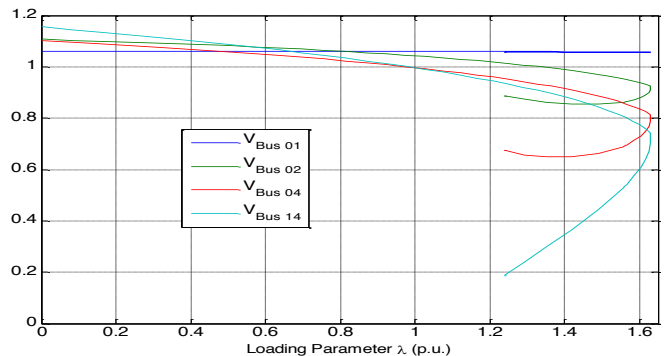

Figure 10: Voltage profile: Model 1: contingency

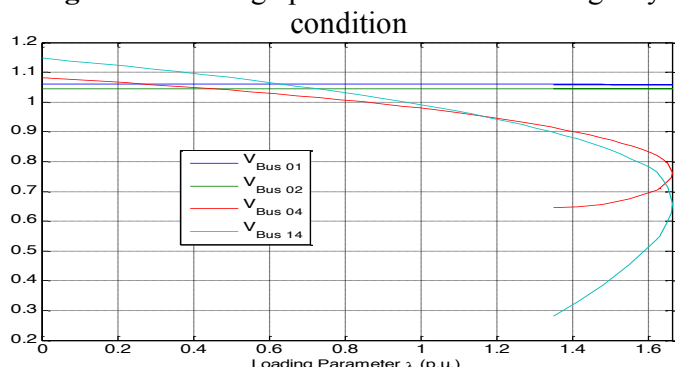

Figure 12: Voltage profile: Model 2: contingency conditions 


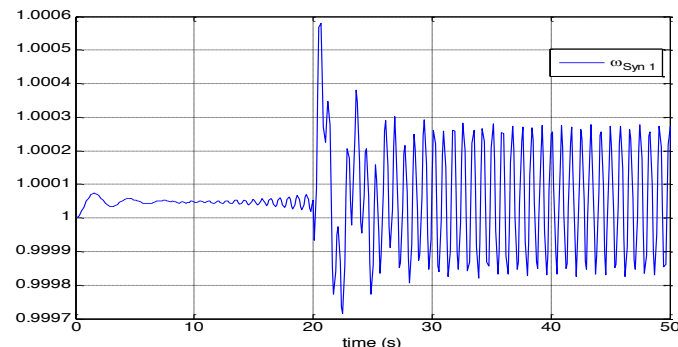

Figure 13: Bus 1 frequency: Model 1

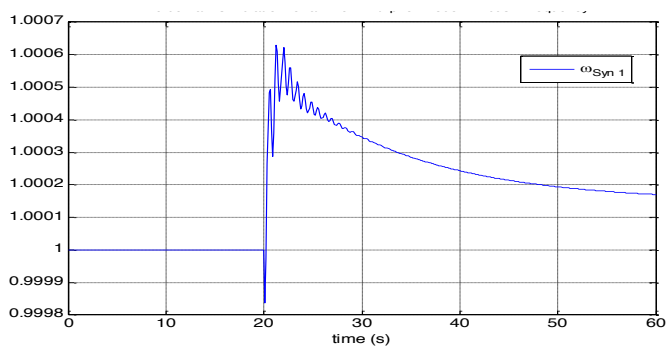

Figure 15: Bus 1 frequency: Model 2

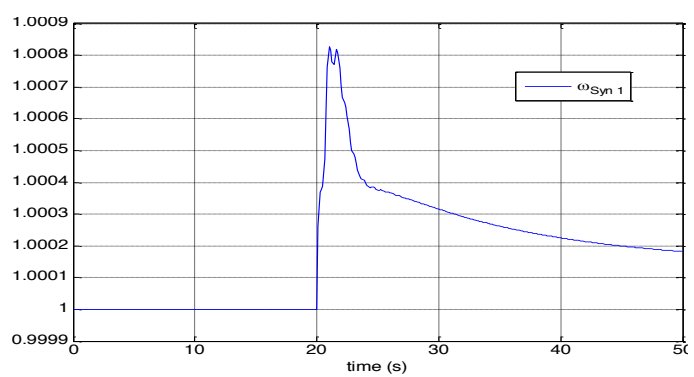

Figure 17: Bus 1 frequency with properly tuned gains: Model 2

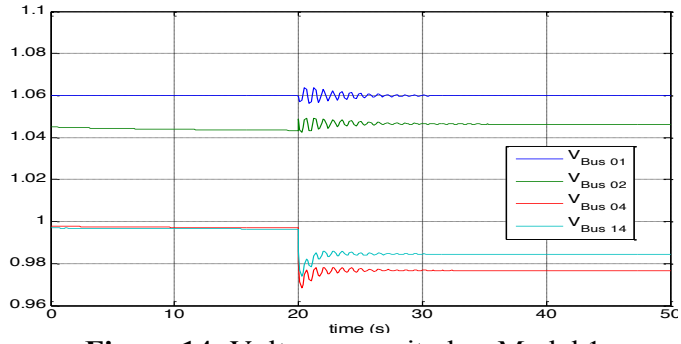

Figure 14: Voltage magnitudes: Model 1

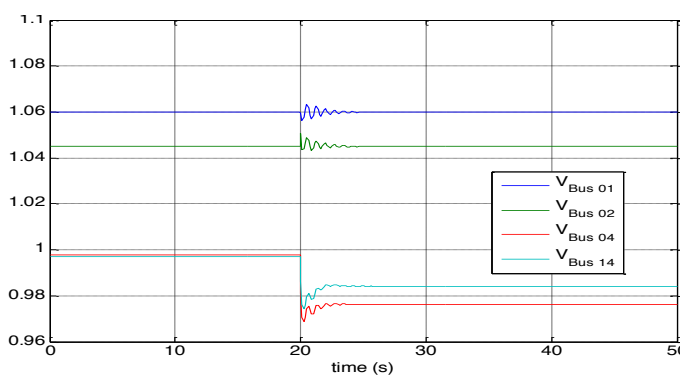

Figure 16: Voltage magnitudes: Model 2

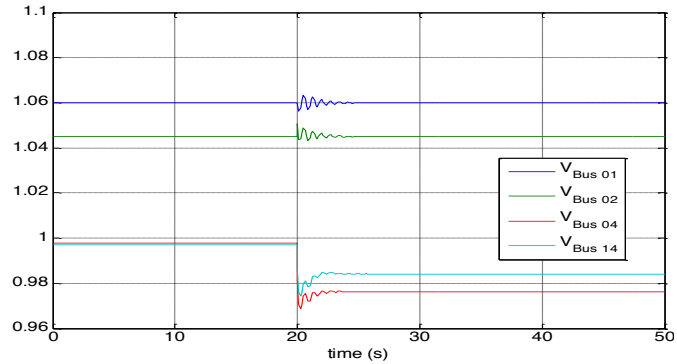

Figure 18: Voltage magnitudes with properly tuned gains: Model 2

\section{Conclusion}

The impact of high PV penetration on power system stability considering the small signal stability analysis, voltage stability analysis and angle stability analysis are successfully investigated in this paper. In this work two different types of PV models are put forward and being analyzed deeply. The detrimental and beneficial impact of both the model are shown at various levels of PV penetration are studied for power system. The comparison for with and without PV penetration are performed and shown. Critical modes are identified using the eigenvalue analysis. Time domain simulation confirms the results. It can conclude that the PV generation in PV-control mode does not much affect the voltage stability compare PQ-control mode. The PV generation may improve system stability by increasing the loadability margin at which oscillatory behaviour can be observed. Also, the effect of tuning the gains is demonstrated. 


\section{References}

[1] www.mnre.gov.in

[2] Behnam Tamimi, Claudio Cañizares, Kankar Bhattacharya, "Modeling and Performance Analysis of Large Solar PhotoVoltaic Generation on Voltage Stability and Inter-area Oscillations" IEEE PES General Meeting, July 2011.

[3] Madhur A. Jagpat, S. L. Shaikh, "The effect of high PV penetration on the small signal stability of the power system using PSAT" Proceedings of ITResearch International Conference, 22nd June 2015.

[4] S. Eftekharnejad, V. Vittal, G. T. Heydt, B. Keel, and J. Loehr, "Impact of increased penetration of photovoltaic generation on power systems," IEEE Trans. Power Syst., vol. 28, no. 2, pp. 893-901, May 2013.

[5] Behnam Tamimi, Claudio Cañizares, and Kankar Bhattacharya, "System Stability Impact of Large-Scale and Distributed Solar Photovoltaic Generation: The Case of Ontario, Canada" IEEE Transactions on Sustainable Energy, Vol. 4, No. 3, July 2013.

[6] Sara Eftekharnejad, Vijay Vittal, Gerald Thomas Heydt, Brian Keel, and Jeffrey Loehr, "Small Signal Stability Assessment of Power Systems With Increased Penetration of Photovoltaic Generation: A Case Study" IEEE Transactions on Sustainable Energy, Vol. 4, No. 4, October 2013.

[7] S. Bu, "Probabilistic analysis of small-signal stability of large-scale power systems as affected by penetration of wind generation", IEEE Trans. Power Syst., vol. 27, no. 2, pp. 762-770, 2012.

[8] P. Kundur, Power System Stability and Control, ser. EPRI Power System Engineering Series. New York, NY, USA: McGraw-Hill, 1994. 